
\title{
BReserch Soutere \\ Problems with diagnosing early stadia of scoliosis due to discrepancies between ATR and the Cobb angle
}

Marek Kluszczyński ( $\nabla$ kluszcztroniny@gmail.com )

Uniwersytet Humanistyczno-Przyrodniczy im Jana Dlugosza w Czestochowie https://orcid.org/00000002-3187-9279

Jacek Wąsik

Uniwersytet Humanistyczno-Przyrodniczy im Jana Dlugosza w Czestochowie

Dorota Ortenburger

Uniwersytet Humanistyczno-Przyrodniczy im Jana Dlugosza w Czestochowie

Research article

Keywords: angle of trunk rotation, early diagnosis of scoliosis, scoliosis prevention

Posted Date: May 5th, 2020

DOI: https://doi.org/10.21203/rs.3.rs-22512/v1

License: (a) (1) This work is licensed under a Creative Commons Attribution 4.0 International License.

Read Full License 


\section{Abstract}

Background This research analysed discrepancies between the angle of trunk rotation (ATR) and the Cobb angle, in order to study if the commonly used $7^{\circ}$ cut-off threshold for ATR helps diagnose scoliosis. In early stadia of scoliosis in children, ATR and the Cobb angle often disagree, increasing the risk of a false diagnosis: while the former does not suggest scoliosis, the latter does.

Methods The study analysed ATR clinical parameters and the Cobb angle in the X-ray pictures of 117 (23 boys and 94 girls, aged 6-17 years) children who had not yet started treatment and whose $\mathrm{X}$-ray pictures showed the Cobb angle of at least $10^{\circ}$, indicating idiopathic scoliosis. The degrees of lumbar lordosis and thoracic kyphosis were measured using the Saunders inclinometer, and back asymmetry was measured with Adam's forward bend test using the Bunnell scoliometer. In the X-ray pictures, the curvature angle was plotted according to the Cobb method. The patients were stratified based on their age, and their ATRs and Cobb angles were compared.

Results Although all the children had the Cobb angle over $10^{\circ}$, in 69 out of 117 (59\%), ATR was below $7 \%$. So, using the $7^{\circ}$ cut-off threshold rule, scoliosis would not be diagnosed in those children. This shows that the two tests often disagree, suggesting that the $7^{\circ}$ cut-off threshold or ATR is ineffective in diagnosing scoliosis.

Conclusions To improve the method for diagnosing scoliosis based on ATR, consideration should be given to lowering the $7^{\circ}$ ATR cut-off threshold.

\section{Background}

Treatment of lateral spinal curvatures in children has changed in the last twenty years. Nowadays, scientists and clinicians gathered around the three most important scientific societies in this field - SRS, SOSORT and IRSSD - stress that, to be effectively treated, scoliosis need to be early diagnosed and followed by conservative medical treatment [1-5]. Consistently applied, the approach leads to a twofold reduction in the number of surgeries for an unchanged incidence rate [6].

The basic criterion to diagnose scoliosis is ATR (Angle of Trunk Rotation), the angle of trunk rotation in Adam's forward bend test. Currently, scoliosis is diagnosed for ATR equal or higher than $7^{\circ}[3,7-9]$.

Ideally, ATR in an X-ray picture should strongly correlate with the Cobb angle, a discrepancy between them being unlikely. If this ideal scenario were the case, scoliosis would be simple to diagnose: should the angle - whether ATR or Cobb - exceed the corresponding cut-off threshold, scoliosis would be diagnosed. And it would not really matter which of the two angles one used, both being equally efficient. The world is not ideal, however - at least not the orthopaedics world. According to the literature, far too often orthopaedists face situations in which one of the two angles exceeds the corresponding threshold while the other does not. So, practice shows that ATR and the Cobb angle are not as correlated as theory 
suggests. Such weak correlation is often observed in the lumbar spine [10]. This phenomenon may lead to both false negative and false positive scoliosis diagnoses.

In this paper, thus, we analyse discrepancies between ATR and the Cobb angle in X-ray pictures of young children who are to start treatment in a scoliosis treatment centre. If we do find significant discrepancies between them, the method for diagnosing scoliosis using either ATR or the Cobb angle should be reconsidered.

\section{Methods}

\section{Hypothesis}

The research verifies the research hypothesis that the $7^{\circ}$ cut-off threshold for ATR is too high to diagnose all instances of scoliosis.

\section{Participants}

The participants were selected from among 351 children of 6-17 years registered in the Children Rehabilitation Centre "Troniny" (which specialized in scoliosis treatment) from January 2011 to September 2014. Included were patients who had a valid X-ray picture of the spinal curvature and showed features of idiopathic scoliosis represented by the Cobb angle of $10^{\circ}$ or greater $[3,11]$. Excluded were those who had other spinal deformities or neurological disorders, especially paresis or paralysis, mental retardation, orthopaedic disorders that may affect the spine, post-traumatic and postoperative conditions of the limbs and spine, and shortening or congenital limb deformities. Out of the 351 children, 117 met these criteria: 23 boys and 94 girls of 6-17 years of age (the mean of 13.0 and the standard deviation of 2.8 years).

\section{Measurements}

The study included the children's clinical assessments, which consisted a degree of lumbar lordosis, a degree of thoracic kyphosis (both measured with a Saunders inclinometer), and back asymmetry (measured using Adam's forward bend test, with the help of a Bunnell scoliometer). Moreover, the children underwent standard medical examinations, including the assessment of the functional length of the lower limbs according to the Derbolowsky test, and the visual and functional assessments of joints of the lower limbs and of the child's gait. In the X-ray pictures, the size of the curvature angle was measured according to Cobb.

To find out whether ATR and the Cobb angle were related, we compared them in the X-rays of the 117 participants. We used the SOSORT consensus [3], which considered three ranges of the Cobb angle in scoliosis: $10-14^{\circ}, 15-21^{\circ}$, and over $21^{\circ}$. Thus, scoliosis is diagnosed when the Cobb angle reaches or exceeds $10^{\circ}$. SOSORT recommends conservative treatment when the Cobb angle exceeds $15^{\circ}$; when it exceeds $21^{\circ}$, brace treatment should be used [12].

\section{Evaluation of the ATR test}


We used the following methods to evaluate the diagnostic value of ATR test: responsiveness testing, specificity testing, and the positive and negative predictive values of the test.

\section{Statistical analysis}

We used the chi-square test to study the agreement between the diagnoses based on ATR and the Cobb angle. Statistical analysis was conducted in R 3.2.5 and checked in MedCalc 16.4.3.

\section{The data}

The raw data are included in the supplementary table.

\section{Results}

Table 1 presents the main characteristics of the participants, including their sex, age category, and scoliosis diagnoses based on the Cobb angle and ATR. Girls predominated (80.7\%), and most children were $13-17$ years old $(59.8 \%)$.

Half of the patients with ATR of $5-6^{\circ}$ had the Cobb angle of $10^{\circ}$ and larger. Together with the children with ATR of $3^{\circ}-4^{\circ}$ and the Cobb angle of $10^{\circ}$ and larger, they constituted $58.9 \%$ of the children with diagnosed scoliosis due to the X-ray (Cobb angle) criterion - and yet, they were not diagnosed as suffering from this disease them using the ATR threshold of $7^{\circ}$. 
Table 1

The main characteristics of the patients.

\begin{tabular}{|lll|}
\hline Characteristics & Frequency $(\boldsymbol{n}=117)$ & Share \\
\hline Sex & & \\
\hline Girls & 95 & 80.7 \\
\hline Boys & 22 & 19.3 \\
\hline Age & 22 & \\
\hline $6-9$ & 25 & 18.8 \\
\hline $10-12$ & 70 & 21.4 \\
\hline $13-17$ & 34 & 59.8 \\
\hline Cobb angle range & \\
\hline $10-14^{\circ}$ & 31 & 29.1 \\
\hline $15-20^{\circ}$ & 52 & 26.5 \\
\hline$>21^{\circ}$ & & 44.4 \\
\hline ATR & 10 & \\
\hline $3-4^{\circ}$ & 59 & 8.5 \\
\hline $5-6^{\circ}$ & 48 & 41.1 \\
\hline$\geq 7^{\circ}$ & & \\
\hline
\end{tabular}


Table 2

Scoliosis diagnosis based on the ATR criterion.

\begin{tabular}{|c|c|c|c|}
\hline & \multirow[t]{2}{*}{ Range of the Cobb angle } & \multicolumn{2}{|l|}{$\begin{array}{l}\text { Scoliosis diagnosis } \\
\text { based on ATR\# }\end{array}$} \\
\hline & & Positive (ATR $\left.\geq 7^{\circ}\right)$ & Negative $\left(\right.$ ATR $\left.<7^{\circ}\right)$ \\
\hline \multirow[t]{3}{*}{ Age of 6-9 } & $10-14^{\circ}$ & 4 & 3 \\
\hline & $15-20^{\circ}$ & 2 & 7 \\
\hline & $\geq 21^{\circ}$ & 3 & 3 \\
\hline \multirow[t]{3}{*}{ Age of $10-12$} & $10-14^{\circ}$ & 1 & 5 \\
\hline & $15-20^{\circ}$ & 3 & 5 \\
\hline & $\geq 21^{\circ}$ & 5 & 6 \\
\hline \multirow[t]{3}{*}{ Age of $13-17$} & $10-14^{\circ}$ & 5 & 16 \\
\hline & $15-20^{\circ}$ & 3 & 11 \\
\hline & $\geq 21^{\circ}$ & 22 & 13 \\
\hline Altogether & $\geq 10^{\circ}$ & 48 & 69 \\
\hline
\end{tabular}

We hypothesised that since ATR over $7^{\circ}$ allows for diagnosing scoliosis, the proportion of children with the Cobb angle of at least $10^{\circ}$ should be significantly higher in this group than in the ATR group below $7^{\circ}$. Ideally, no children with the Cobb angle of $10^{\circ}$ would have ATR below $7^{\circ}$, a situation representing full agreement (correlation) between the two methods. The chi-square test applied to verify the null hypothesis of no difference between the groups (children of ATR below and $7^{\circ}$ or higher) gave the value of $1.884(\mathrm{df}=1 ; p=0.09)$, meaning the hypothesis should not be rejected. Thus, the proportion of children diagnosed with scoliosis using the Cobb angle did not significantly differ between the groups of children diagnosed and not diagnosed with scoliosis using ATR. So, the two methods often disagree. These results can mean that using $7^{\circ}$ threshold of ATR to diagnose scoliosis is incorrect. 
Table 3

The assessment of the ATR test with the $7^{\circ}$ criterion for scoliosis diagnosis.

\begin{tabular}{|llll|}
\hline Test trait & \multicolumn{3}{l|}{ Group age } \\
\hline & $6-9$ & $10-12$ & $13-17$ \\
\hline Responsiveness & $55.6 \%$ & $88.9 \%$ & $83.3 \%$ \\
\hline Specificity & $23.1 \%$ & $31.3 \%$ & $40.0 \%$ \\
\hline Positive predictive value & $33.3 \%$ & $42.1 \%$ & $51.0 \%$ \\
\hline Negative predictive value & $42.9 \%$ & $83.3 \%$ & $76.2 \%$ \\
\hline
\end{tabular}

Table 3 shows the assessment of the diagnostic method based on ATR measurement with the $7^{\circ}$ criterion for scoliosis diagnosis. In the 6-9 years old age group, the ATR test indicated scoliosis in only $55.5 \%$ of the children. The method worked much better for older children, for which it correctly diagnosed scoliosis in $88.9 \%$ of the children in the $10-12$ years old group and in $83.3 \%$ of the children in the $13-17$ years old group.

\section{Discussion}

The method for diagnosing scoliosis based on ATR uses the phenomenon that vertebral rotation occurs in scoliosis, that is, spatial deformation of the spine in the transverse plane [3, 7]. The method based on the Cobb angle, on the other hand, uses the phenomenon that scoliosis is accompanied by the spine lateral bending, and so it measures changes in the position of individual vertebrae in relation to each other in the frontal plane [12]. To detect interference in the presence of curvature, the ATR method estimates correlation between the co-occurrences of spinal deformities in the two planes $[1,3,4,7,8]$. Proper interpretation of ATR is possible when the lateral bending in the frontal plane corresponds to a linear increase in the rotation of the vertebrae. In clinical practice, however, these parameters often poorly correlate, especially in young children (6-9 years) with scoliosis in the lumbar region $[1,10,13-14]$.

Scoliosis will unlikely be diagnosed in its early stadium in young children whose Cobb angle is $15^{\circ}$ or greater (representing quite an advanced stadium of scoliosis) but ATR below $7^{\circ}$. Many studies have indicated the need for putting such children under active surveillance for scoliosis development as well as introducing active prophylaxis as early as at ATR of $5^{\circ}[15]$. The best treatment results so far are obtained thanks to the early detection of scoliosis, followed by introducing exercises devoted to scoliosis (Physiotherapeutic Scoliosis Specific Exercises, PSEE) and - if necessary - bracing [16-22].

Some children with scoliosis have so-called side shifting, which is a lateral trunk shift at the L2-L4 level, clinically reflected in high asymmetries of the waist angles [23] and scoliosis of about $10^{\circ}-15^{\circ}$ in an Xray (the Cobb angle) -but a trunk rotation of $3-5^{\circ}$ (ATR). Figure 1 presents the hypo-rotationality of such scoliosis. The torso rotation angle would be in this situation smaller than it appears from the lateral 
bending value, represented by the Cobb angle in the X-ray picture.

In such situations, ATR and the Cobb angle are not correlated, with a serious consequence: while the former suggests a patient does not suffer from scoliosis, the latter indicates it has reached an advanced stadium. Failing to include such a child in active prevention may result in the development of double-arch scoliosis in the following years. Sometimes this phenomenon is accompanied by a functional inequality of lower limbs and oblique alignment of spina iliaca posterior superior (SIPS) [23]. This situation is more common in younger children, aged 6-9 years. The development of idiopathic scoliosis in an early stadium is reflected in low-degree scoliosis of ATR below $7^{\circ}$.

A lack of correlation between the lateral bending of the spine and vertebral rotation may be responsible for an imprecise diagnosis of scoliosis in children based on the $7^{\circ}$ ATR threshold, especially when a child has joint laxity or pelvis asymmetry $[13,14,24-26]$. Based on the results presented in this paper, we can hypothesise that correlation between ATR and the Cobb angle can help diagnose hypo-rotational, normorotational, and hyper-rotational scoliotic spinal deformation (Fig. 2).

In hypo-rotational scoliosis (Fig. 3 shows an example), ATR is smaller than the Cobb angle, and so their correlation is small, with small rotations of the vertebrae accompanied by a high lateral curvature of the spine. This is particularly common in younger children.

In normo-rotational scoliosis (Fig. 4), ATR and the Cobb angle are about the same (so their correlation is high), and so the degree of lateral bending of the spine corresponds to the degree of vertebral rotation [27].

In hyper-rotational scoliosis, ATR is higher than the Cobb angle (so their correlation is low), and high rotations of the vertebrae are accompanied by the slight lateral bending of the spine (Fig. 5). Hyperrotational scoliosis is rare.

An issue arises as to whether the three types of correlation between ATR and the Cobb angle need to be distinguished. For a person diagnosing scoliosis and qualifying children for treatment, but also for those very children, the ability to distinguish them can be crucial. In the light of the results presented here, merely using one of the two criteria to diagnose scoliosis can be insufficient to diagnose the three scoliosis types discussed above. Combining the two criteria the way we propose reduces the risk that a child whose ATR is well below the threshold of $7^{\circ}$ - and so suffers from hypo-rotational scoliosis - is not qualified for treatment.

A related issue is whether the threshold should be decreased to $5^{\circ}$, especially for children aged 6-10 years. In Samuelsson's reports investigating relations between ATR and the Cobb angle in X-ray images, 
the correlation coefficient was low (0.57-0.65). In an extreme example, the Cobb angle of $25^{\circ}$ corresponded to ATR of $7^{\circ}$ in the thoracic segment and of $6^{\circ}$ in the lumbar section [28]. Carlson et al. pointed out that between-patient variation in ATR-Cobb correlation might be due to between-patient variation in spinal elasticity [27].

\section{Conclusions}

The present study provided empirical data indicating that the common approach to the classification of scoliosis - which uses a $7^{\circ}$ threshold for ATM as an indication of scoliosis - is questionable. We are aware that the results can amaze: They suggest the current approach to diagnosing scoliosis based on ATR needs immediate reconsideration.

If everything worked just fine, the number of children with the Cobb angle of $10^{\circ}$ and above would have been significantly higher among children with ATR of at least $7^{\circ}$ than among children with ATR below $7^{\circ}$. It was not so, however, as statistical analysis showed. So, the $7^{\circ}$ ATR threshold does not work the way it should.

Due to the serious long-term consequences of the difficulties in diagnosing scoliosis at its early stadia, systematic research has been conducted to precisely examine individual conditions of the existing barriers in the diagnosis of the spine lateral curvature [29,30]. This study adds to this topic, offering new and important insights on how scoliosis should be diagnosed in children.

From the study it follows that a significant percentage of children with back asymmetry within the ATR range of $5-6^{\circ}$ may show features of idiopathic scoliosis. Therefore, the common $7^{\circ}$ cut-off ATR threshold for diagnosing scoliosis failed to detect many instances of scoliosis at its early stadium. If confirmed in further research, this observation would call for an immediate change in diagnosing early scoliosis in children from 6 to 12 years old: the ATR threshold should be decreased from $7^{\circ}$ to $5^{\circ}$.

\section{Declarations}

\section{Ethics approval and consent to participate}

The research is part of a larger study, approved by the Bioethics Committee of the Regional Medical Chamber in Częstochowa, Poland (the act number K.B.Cz.-0001/2014, 29 January, 2014). The study was performed in accordance with the ethical standards as laid down in the 1964 Declaration of Helsinki and its later amendments.

The parents (or custodians) of the patients signed agreements to process the data related to their children's medical assessment and examinations and to publish the corresponding data in an anonymous manner.

\section{Consent for publication}


The parents (or custodians) of the children presented on the photograph and the two x-rays also gave their consent to use these pictures in the publication.

\section{Availability of data and materials}

The dataset supporting the conclusions of this article is included within the article (and its additional file).

\section{Competing interests}

The first author (MK) is the co-owner of the Children Rehabilitation Centre "Troniny", where the study was conducted. The other two authors do not declare any conflicts of interest.

\section{Funding}

No external funding was used to carry out this research.

\section{Author Contributions}

MK designed the experiment and conducted the experiment and contributed to drafting and revising the manuscript. JW and DO substantively revised the manuscript. All authors have read and approved the final submitted manuscript. All the authors have approved the submitted version

\section{References}

1. Grivas TB, Vasiliadis ES, Mihas C, Savvidou O. The effect of growth on the correlation between the spinal and rib cage deformity: implications on idiopathic scoliosis pathogenesis. Scoliosis $2007 ; 2 ; 11$.

2. Kotwicki T. Evaluation of scoliosis today: examination, X-rays and beyond. Disabil Rehabil. 2008;30:742-51.

3. Negrini S, Donzelli S, Aulisa AG, Czaprowski D, Schreiber S, de Mauroy JC, et al. SOSORT guidelines: orthopaedic and rehabilitation treatment of idiopathic scoliosis during growth. Scoliosis 2012;7;3.

4. Bunnell WP. An objective criterion for scoliosis screening. J Bone Joint Surg Am. 1984;66:1381-7.

5. Burwell RG, Cole AA, Cook TA, Grivas TB, Kiel AW, Moulton A, et al. Pathogenesis of idiopathic scoliosis. The Nottingham concept. Acta Orthop Belg. 1992;58:33-58.

6. Rigo M, Reiter C, Weiss HR. Effect of conservative management on the prevalence of surgery in patients with adolescent idiopathic scoliosis. Pediatric Rehabil. 2003;6:209-14.

7. Bunnell WP. Outcome of spinal screening. Spine. 1993;18:1572-80.

8. Huang SC. Cut-off point of the scoliometer in school scoliosis screening. Spine 1997;22;1985-1989.

9. Pruijs JE, Keessen W, van der Meer R, van Wieringen JC, Hageman MA. School screening for scoliosis: methodologic considerations. Part 1: External measurements. Spine (Phila Pa 1976). 
1992;17:431-6.

10. Cote P, Kreitz BG, Cassidy JD, Dzus AK, Martel J. A study of the diagnostic accuracy and reliability of the Scoliometer and Adam's forward test. Spine. 1998;23:796-802.

11. Bunnell WP. An objective criterion for scoliosis screening. J Bone Joint Surg Am. 1984;66:1381-7.

12. Negrini S, Zaina F, Romano M, Negrini A, Parzini S. Specific exercises reduce brace prescription in adolescent idiopathic scoliosis: A prospective controlled cohort study with worst-case analysis. J Rehabil Med. 2008;40:451-5.

13. Fazal M, Edgar M. Detection of adolescent idiopathic scoliosis. Acta Orthop Belg. 2006;72:184-6.

14. Grivas TB, Hresko MT, Labelle H, Price N, Kotwicki T, Maruyama T. The pendulum swings back to scoliosis screening: screening policies for early detection and treatment of idiopathic scoliosis current concepts and recommendations. Scoliosis 2013;8;16.

15. Labelle H, Richards SB, De Kleuver M, Grivas TB, Luk KD, Wong HK, et al. Screening for adolescent idiopathic scoliosis: an information statement by the scoliosis Research Society International Task Force. Scoliosis 2013;8;17.

16. Asher MA, Burton DC. Adolescent idiopathic scoliosis: natural history and long term treatment effects. Scoliosis 2006;1;2.

17. Grivas TB, Wade MH, Negrini S, O’Brien JP, Maruyama T, Hawes MC, et al. SOSORT consensus paper: school screening for scoliosis: Where are we today? Scoliosis 2007;2;17.

18. Lee CF, Fong DY, Cheung KM, Cheng JC, Ng BK, Lam TP. Costs of school scoliosis screening: a large, population-based study. Spine. 2010;35:2266-72.

19. Ashworth MA, Hancock JA, Ashworth L, Tessier KA. Scoliosis screening. An approach to cost/benefit analysis. Spine. 1988;13:1187-8.

20. Thilagaratnam S. School-based screening for scoliosis: is it cost-effective? Singapore Med J. 2007;48:1012-7.

21. Weinstein SL, Dolan LA, Wright JG, Dobbs MB. Effects of bracing in adolescents with idiopathic scoliosis. N Engl J Med. 2013;369:1512-21.

22. Grivas TB, Vasiliadis ES, Koufopoulos G, Segos D, Triantafyllopoulos G, Mouzakis V. Study of trunk asymmetry in normal children and adolescents. Scoliosis 2006;1;19.

23. Burwell RG, James NJ, Johnson F, Webb JK, Wilson YG. Standardised trunk asymmetry scores. J Bone Join Surg. 1983;4:452-63.

24. Carlson BB, Burton DC, Asher MA. Comparison of trunk and spine deformity in adolescent idiopathic scoliosis. Scoliosis 2013;8;2.

25. Czaprowski D, Kotwicki T, Pawłowska P, Stoliński L. Joint hypermobility in children with idiopathic scoliosis: SOSORT award 2011 winner. Scoliosis 2011;6;22.

26. Rigo M. Pelvis asymmetry in idiopathic scoliosis. Evidence of whole torsional body deformity? Stud Health Technol Inform. 1997;37:63-5. 
27. Carlson B, Douglas B, Asher M. Comparison of trunk and spine deformity in adolescent idiopathic scoliosis. Scoliosis 2013;8;2.

28. Samuelsson L, Noren L. Trunk rotation in scoliosis. The influence of curve type and direction in 150 children. Acta Orthop Scand. 1997;68:273-6.

29. Kluszczyński M, Wąsik J, Ortenburger D, Zarzycki D, Siwik P. Prognostic value of measuring the angles of lumbar lordosis and thoracic kyphosis with the Saunders inclinometer in patients with low back pain. Pol Ann Med. 2017;24:13-35.

30. Ortenburger D, Szerla M, Kluszczyński M. Exercise and psychological factors in low back pain. Phys Act Rev. 2017;5:1-5.

\section{Figures}

2

Figure 1

An 11-year old girl with scoliosis type Th-L sin, Cobb $17^{\circ}$, ATR $4^{\circ}$ Th-L sin.

ATR. $<7^{\circ}$ Cobb. $\geq 15^{\circ}$

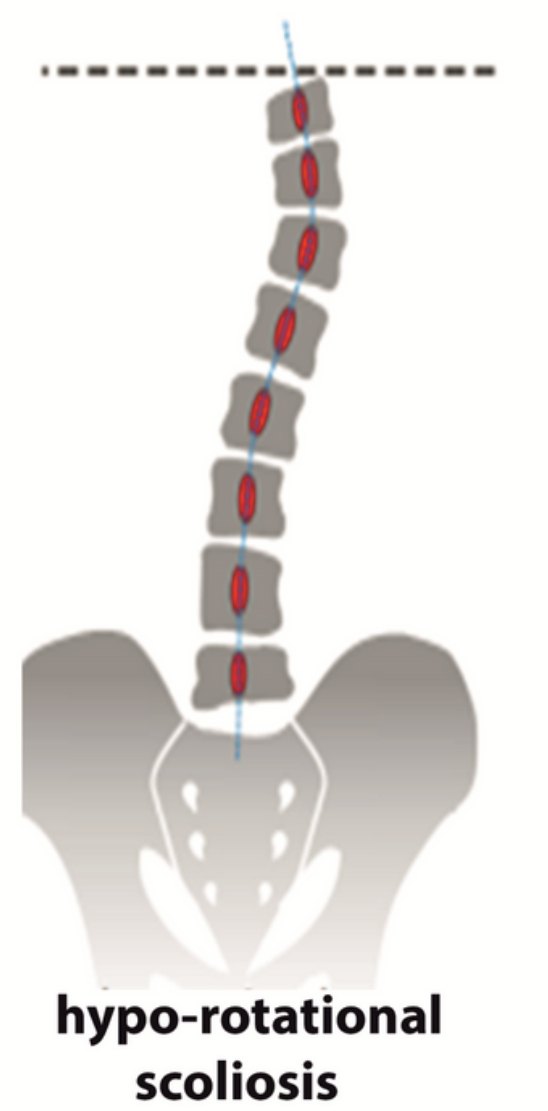

ATR. $\geq 7^{\circ}$ Cobb. $\geq 15^{\circ}$

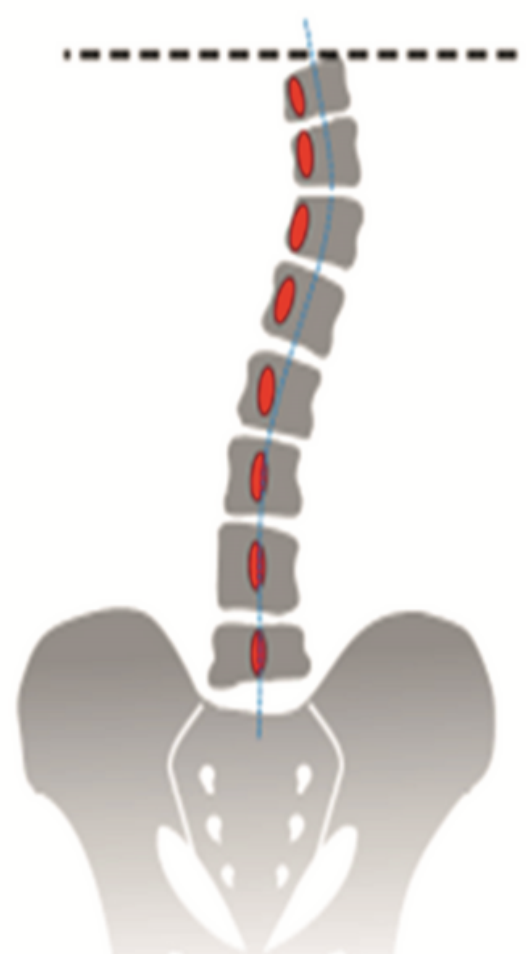

normo-rotational scoliosis
ATR. $\geq 7^{\circ}$ Cobb. $<15^{\circ}$

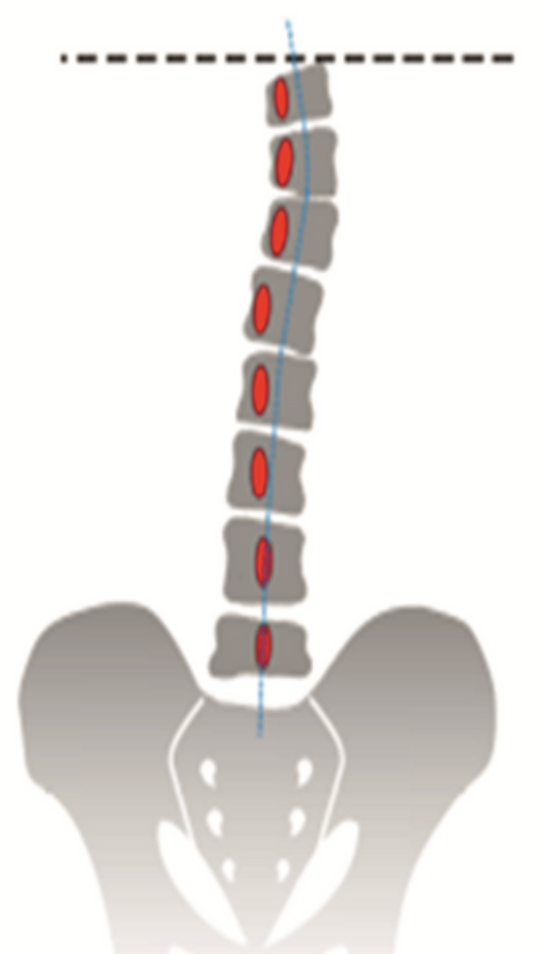

hyper-rotational scoliosis 
Figure 2

The vertebral column in scoliosis: How to combine the ATR and Cobb angle measurements.
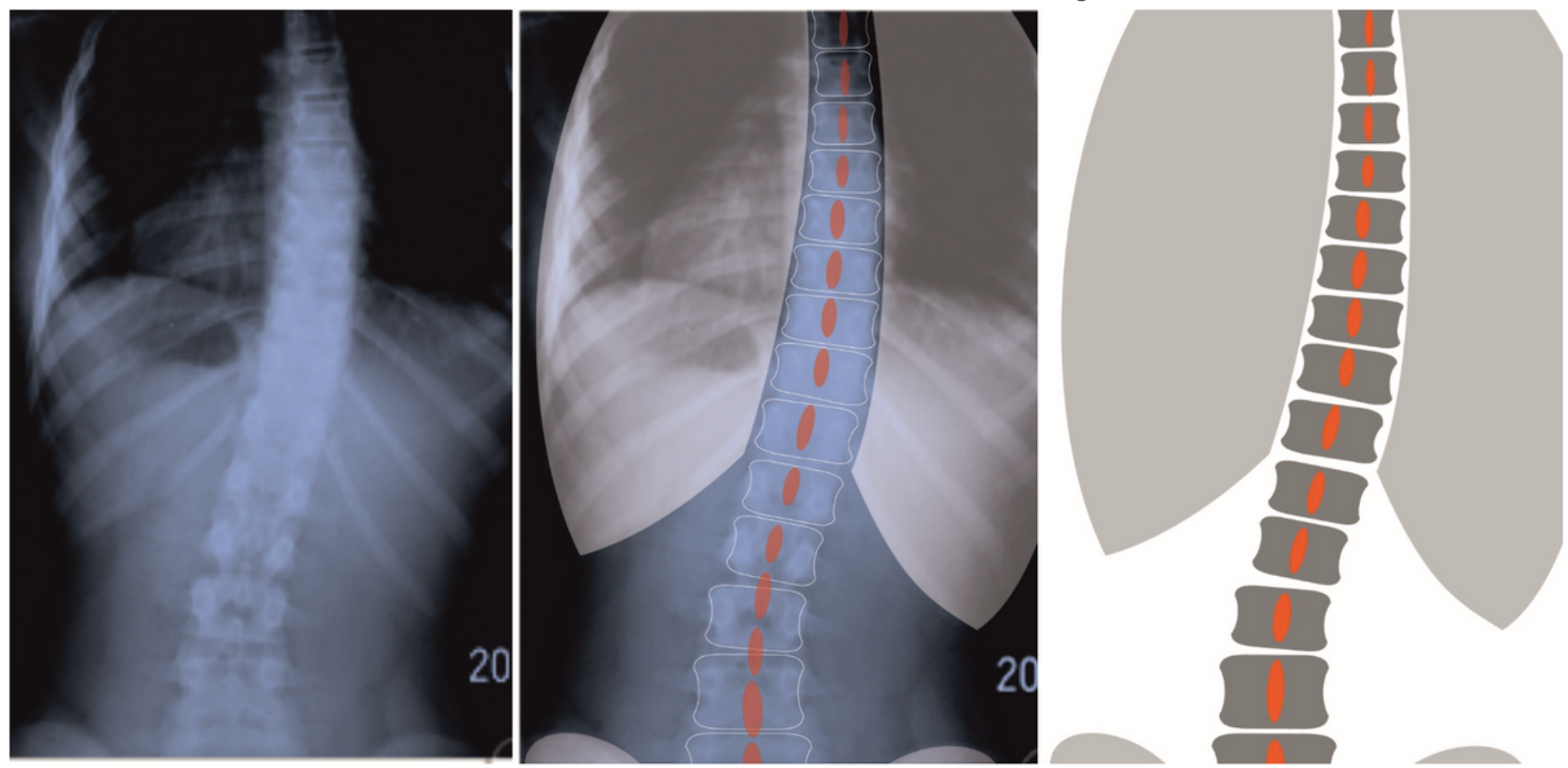

\section{Figure 3}

Hypo-rotational scoliosis, with ATR $\left(4^{\circ}\right)$ smaller than the Cobb angle $\left(15^{\circ}\right)$.

2

\section{Figure 4}

Normo-rotational scoliosis, with similar ATR and the Cobb angle. Scoliosis right Th4-Th10 Cobb-28 ${ }^{\circ}$, ATR $8^{\circ}$, left Th11-L4 Cobb 28, ATR $9^{\circ}$.

展

\section{Figure 5}

Hyper-rotational scoliosis, with ATR $\left(8^{\circ}\right)$ higher than the Cobb angle $\left(6^{\circ}\right)$.

\section{Supplementary Files}

This is a list of supplementary files associated with this preprint. Click to download.

- Supplementarytable.xlsx 